\title{
RECENT ADVANCES IN INFRA-RED SOLAR SPECTROSCOPY
}

\author{
BY L. GOLDBERG
}

McMath-Hulbert Observatory of the University of Michigan, Pontiac, Michigan

CONTENTS

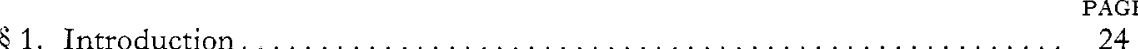

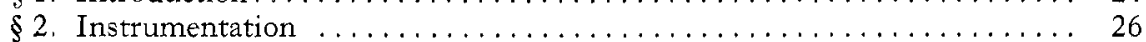

$\S 3$. An atlas of the infra-red solar spectrum................. 28

$\S 4$. Solar lines.................................... 29

Factors governing the appearance of solar lines............ 34

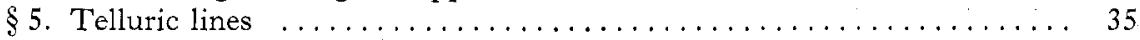

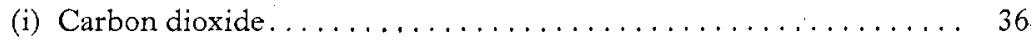

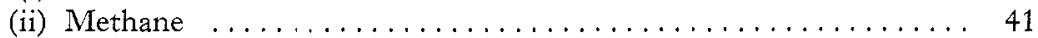

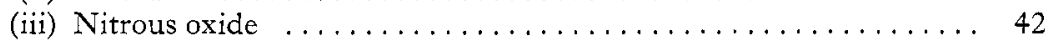

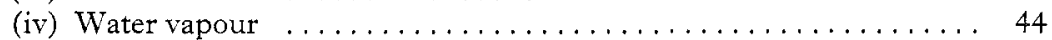

Acknowledgments $\ldots \ldots \ldots \ldots \ldots \ldots \ldots \ldots \ldots \ldots \ldots \ldots \ldots, 44$

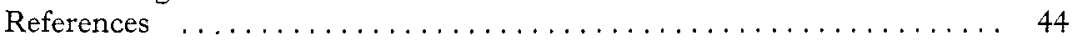

\section{\$1. INTRODUCTION}

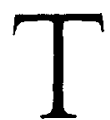

$\mathrm{HE}$ existence of both infra-red and ultra-violet radiation was demonstrated by Sir William Herschel (1800), who observed the heating effects of invisible solar rays on a thermometer placed in the focal plane of his spectroscope. The first 'map' of the infra-red solar spectrum was Sir John Herschel's (1840) Thermograph, which he prepared by projecting the spectrum on a strip of dull black paper moistened with alcohol. The damp spots remaining on the paper after exposure to radiation indicated the presence and location of absorption bands. The primitive detection methods employed by the Herschels were soon superseded by the advent of the thermocouple which was discovered by Seebeck (1826), followed by Nobili's (1831) invention of the thermopile, and the application of the phosphor method by A. E. Becquerel (1843 et seq.). The latter eventually mapped the spectrum to an infra-red limit of about $1.4 \mu$. Draper (1843) also used the phosphor technique to observe three wide infra-red bands (alpha, beta, and gamma), the existence of which were later verified by Foucault and Fizeau (1847) with thermocouples. The phosphor method of observation was considerably improved by A. H. Becquerel (1883), who mapped the solar spectrum to $1.4 \mu$, with a $\mathrm{CS}_{2}$ prism and Rutherford grating. He was also the first to note the changing appearance of telluric absorption bands due to variations in atmospheric conditions and in solar altitude.

The years following these early developments have seen steady progress in the exploration of the infra-red solar spectrum, due both to the design of more efficient optical systems, and to the development of highly sensitive energy detectors. Advances in detection methods have resulted from improvements both in photographic emulsions and in devices for more or less instantaneous energy recording. The first application of the photographic method was made by Draper (1881) with a silver bromide plate placed on a phosphorescent screen 
exposed to infra-red radiation. Abney (1880) employed what is now conventional photography in recording wavelengths slightly longer than $1 \mu$, and later (1886) achieved the first photographic map of the infra-red spectrum, from $0.69 \mu$ to $1 \mu$, using a Rowland concave grating. He was the first to resolve and measure infra-red absorption lines, claiming a precision of $0.1 \mathrm{~A}$. for his wavelength determinations. Improved photographic maps of the solar spectrum extending to about $1 \mu$ were published by Higgs (1898), Meggers (1918), Burns (1920), and Brackett (1921).

More recently, St. John, Moore, Ware, Adams, and Babcock (1928). have listed 1,700 wavelengths between $\lambda 7330$ and $\lambda 10,216$ in a supplement to the Revision of Rowland's Preliminary Table of Solar Spectrum Wavelengths. Finally, the application of the photographic process to the infra-red solar spectrum has culminated in the publication by Babcock and Moore (1947), after 22 years of preparation, of an infra-red extension to the Revised Rowland. The 'IRE' contains wavelengths for about 7,400 lines in the region $\lambda 6600-\lambda 13,495,51 \%$ of which are due at least in part to atmospheric absorption. Of the remaining lines, $38 \%$ are certainly or probably solar, and $11 \%$ of the lines are so weak that their origin is uncertain. Well over one-half of the solar lines have been identified with known atoms and molecules. The precision of the measured wavelengths is extremely high, the errors being less than one part in a million for wavelengths shorter than $1.21 \mu$.

Although the photographic method has yielded much higher spectral resolution than have other types of infra-red detection, its application thus far has been limited to wavelengths shorter than $1.4 \mu$. On the other hand, bolometers, thermocouples and thermopiles have been successfully employed to map the solar spectrum to an optical limit of $24 \mu$. Lamansky (1872) used an insensitive thermopile to map the solar prismatic spectrum, recording three large gaps in the infra-red spectrum in verification of Draper's observations. Lamansky was the first to attribute these bands to absorption by the earth's atmosphere. In 1881, Langley began his epic investigations of the infra-red solar spectrum, which were later continued at the Smithsonian Institution by Abbot, Fowle, and Freeman. Langley's achievements were made possible by his independent invention and introduction to infra-red spectroscopy of the sensitive bolometer. The earlier discovery of this detector by Svanberg (1857) appears to have escaped general notice. By 1888, Langley had obtained a continuous record of the solar spectrum from the ultra-violet cut off at $0 \cdot 3 \mu$ to a long wavelength limit of $5 \cdot 3 \mu$. Langley was able to detect, but not to record, radiation of longer wavelengths. Fowle(1917) extended the spectrum to $13 \mu$, and Abbot and Freeman (1929) mapped the solar spectrum from $\lambda 7582$ to $\lambda 18,194$ with sufficient accuracy to resolve strong solar absorption lines near $1 \mu$.

The thermocouple has been used with great success by Adel and by Migeotte. The former (1942) has recently extended the prismatic solar spectrum from $14 \mu$ to $24 \mu$ and has mapped (1941a) the grating spectrum from $2 \mu$ to $14 \mu$ with a theoretical resolving power of about 10,000 . Migeotte $(1945,1948)$ has achieved the highest resolution thus far obtained with grating and thermocouple in the regions between $1.3 \mu$ and $1.5 \mu$ and between $2.7 \mu$ and $5.5 \mu$.

As at the end of 1946, the status of infra-red solar spectroscopy could be roughly summarized by the statement that the spectrum had been mapped photographically with fine detail to about $1.4 \mu$ and with considerably lower 
resolution with various types of heat detectors to $24 \mu$. (We do not consider here the post-war developments in radio-wave spectroscopy, by means of which solar radiation has been detected in the wavelength region $1 \mathrm{~cm}$. to $15 \mathrm{~m}$.) The most recent advance in infra-red solar spectroscopy in the region $1.4-3.6 \mu$ has been achieved at the McMath-Hulbert Observatory by a group of workers headed by Dr. Robert R. McMath, and including Dr. Orren C. Mohler, Dr. A. Keith Pierce and the writer. The Michigan group have made use of lead sulphide photoconductive cells and a high-dispersion grating spectrometer to map the spectrum with resolution comparable with that which can be obtained photographically at shorter wavelengths.

Lead sulphide cells were first employed as infra-red detectors in Germany during World War II and were later developed in Great Britain by Starkiewicz, Sosnowski, and Simpson (1946) at the Admiralty Research Laboratory and in the United States by Cashman (1946) at Northwestern University. The PbS cells are sensitive from well below $1 \mu$ to $3 \cdot 6 \mu$. Maximum sensitivity can occur at any wavelength between $1 \mu$ and $3 \mu$ depending on the mode of construction of the photoconductive layer. The cells operate satisfactorily at room temperature; but refrigeration to $-80^{\circ} \mathrm{C}$. increases the signal-to-noise ratio by a factor of about ten and also shifts the sensitivity maximum to longer wavelengths. The response time of the cells is of the order of microseconds and the resistance is in the neighbourhood of one megohm. These characteristics lend themselves to A.c. amplification, with interruption frequencies of the order of $1,000 \mathrm{c} / \mathrm{s}$. Amplifiers designed for use with the Cashman $\mathrm{PbS}$ cells have been developed by Wilson (Kuiper, Wilson, and Cashman 1947).

The performance of the Admiralty Research Laboratory cells at a temperature of $-78^{\circ} \mathrm{C}$. was studied by Sutherland, Blackwell and Fellgett (1946), who found a signal-to-noise ratio at $2.6 \mu$ about 100 times that of the Hilger-Schwarz thermocouple. With a non-echelette grating of 14,400 lines per inch and slit widths of $0.08 \mathrm{~cm}^{-1}$ they were able to resolve lines of $\mathrm{H}_{2} \mathrm{O}$ at $3,970 \mathrm{~cm}^{-1}$ as close as $0.14 \mathrm{~cm}^{-1}$ apart. Previously, the closest pair of lines resolved in the same band had a separation of $0.6 \mathrm{~cm}^{-1}$. Sutherland, Blackwell and Fellgett concluded that an additional gain in resolving power, up to a factor of two, could be attained with improved spectrometer optics.

The majority of the $\mathrm{PbS}$ cells constructed by Cashman have been used at room temperature. Cashman states that the peak sensitivity of his uncooled cells is about 1,000 times greater than the sensitivity of thermocouple receivers.

\section{§2. INSTRUMENTATION}

The instrumentation involved in the application of the Cashman cells to the infra-red solar spectrum has been described in detail by McMath and Mohler (1949). The schematic diagram in Figure 1 shows the optical layout of the all-mirror image-forming and dispersing systems in the 70-foot McGregor solar tower. The four mirrors and $\mathrm{CaF}_{2}$ prism between $\mathrm{S}_{1}$ and $\mathrm{S}_{2}$ form a predispersing unit. The Pfund-type spectrometer has a focal ratio of 50 , the focal lengths of the collimating and focusing mirrors being 277 inches. Scanning of the spectrum by the $\mathrm{PbS}$ cell is accomplished by rotation of the grating at any one of three rates : $\frac{3}{10}, \frac{3}{4}$ or $1 \frac{1}{2}$ degrees per hour. Two gratings, ruled 15,000 lines per inch and 5,000 lines per inch, have been employed for the spectral regions $1 \cdot 0-2 \cdot 5 \mu$ and $2 \cdot 9-3 \cdot 6 \mu$, respectively. 
The $\mathrm{PbS}$ cells in use at the McMath-Hulbert Observatory have all been especially constructed by Dr. Cashman, who has provided cells of both uncooled and cooled types with envelopes of glass and of fused silica respectively. The silica cell is shaped like a Dewar flask and is cooled by a mixture of solid carbon dioxide and acetone. The A.C. amplifier was designed and constructed by Wilson to match the characteristics of the Cashman cells.

The output of the amplifier is passed to a Leeds and Northrup Speedomax Recorder, which traces the spectrum in Indian ink on unruled white paper. For the three different rates of grating rotation, the dispersions of the spectrum

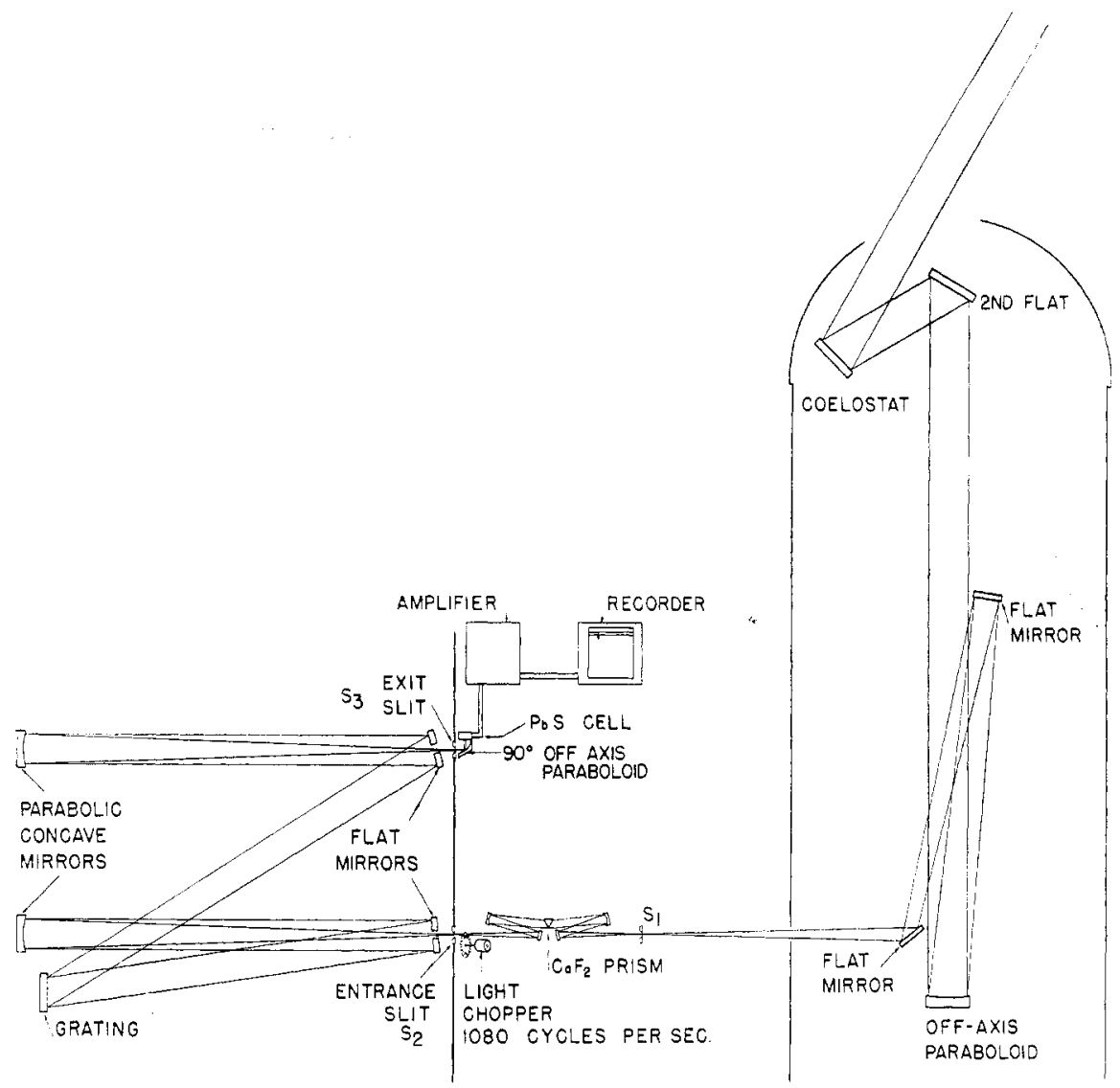

Figure 1. Schematic view of the McGregor tower and spectrometer of the McMath-Hulbert Observatory.

in $\mathrm{mm} / \mathrm{A}$. at $\lambda 20,000$ are 3,6 , and 12 respectively. A careful study has been made of the relation between relative radiation intensity and recorded deflection, with the result that the response has been found to be very closely linear for all deflections greater than $2 \mathrm{~cm}$. The amplifier gain is usually adjusted so that the continuous spectrum produces a deflection of about $20 \mathrm{~cm}$. This means that intensity measurements may be made directly on the tracings for all but the very strongest lines.

Infra-red wavelength standards have been established by Rowland's method of overlapping orders with reference to Fraunhofer lines visible in the third and fourth order grating spectra. It is estimated that an accuracy of about one 
part in 200,000 is obtainable by this method, the limiting factors being uncertainty as to the index of refraction of air in the infra-red, and slight irregularities in the motions of the grating and recording paper. The accuracy obtained is more than adequate for purposes of identification and is sufficient for the fairly accurate evaluation of molecular constants.

A measure of the overall performance of the spectrometer is afforded by the separation of close pairs of lines just clearly resolved on the tracings. Such measures are given in Table 1 for various wavelengths from $\lambda 12,000$ to $\lambda 36,000$ and for both the Mount Wilson and Michigan gratings. The numbers in

Table 1. Measured Separations of Barely Resolved Line Pairs in the Infra-Red Solar Spectrum.

(The numbers in parentheses are the separations corresponding to the theoretical resolving power.)

\begin{tabular}{|c|c|c|c|c|c|c|}
\hline Wavelength region (A.) & 12,000 & 16,000 & 20,000 & 24,000 & 32,000 & 36,000 \\
\hline Mt. Wilson grating, & & & & & & \\
\hline Tichigat & $0.2(012)$ & $0.12(0.03)$ & $010(0.0 \%)$ & $0.07(0)$ & & \\
\hline 24,139 lines $\left(\mathrm{cm}^{-1}\right)$ & $0.52(0.35)$ & $0.33(0.26)$ & $0.28(0.21)$ & $0.23(0 \cdot 17)$ & $0 \cdot 14(0 \cdot 13)$ & $0 \cdot 13(0 \cdot 11)$ \\
\hline
\end{tabular}

parentheses refer to the separations corresponding to the theoretical resolving powers of the two gratings. Approximately $80 \%$ of the theoretical resolving power of each grating has been attained. Since neither grating is optically perfect, it seems probable that the full realization of the possibilities of the lead-sulphide cell must await the development of improved gratings.

As a result of a cooperative arrangement with the Mount Wilson and Palomar Observatories, the McMath-Hulbert Observatory has recently installed a nearduplicate of its infra-red spectrometer on the Snow Telescope on Mount Wilson. The objective mirror of the Snow Telescope is 24 inches in diameter and is figured at $\mathrm{f} / 30$. Observations have been in progress since May 1949. The tracings secured thus far are definitely of superior quality, due to the increased transparency and lower water vapour content of the Mount Wilson atmosphere as compared with that over Michigan.

\section{§3. AN ATLAS OF THE INFRA-RED SOLAR SPECTRUM}

The instrumentation described above has been employed in a series of investigations of the infra-red solar spectrum at the McMath-Hulbert Observatory. Tracings have been secured both at Lake Angelus and at Mount Wilson covering the entire spectral region from 0.8 to $3 \cdot 6 \mu$. The Mount Wilson records have been incorporated into an atlas of the infra-red solar spectrum, to be published shortly. The atlas will consist of approximately 250 tracings, each about $70 \mathrm{~A}$. in length, and embracing the spectral region from 0.8 to $2.5 \mu$. In order to achieve some degree of uniformity in the intensities of the telluric lines, the atlas observations were confined to the period from two hours before to two hours after noon on days of relatively low humidity. The infra-red atlas is intended to overlap and to extend the elaborate Utrecht Atlas (Minnaert, Mulders and Houtgast 1940) which terminates at $\lambda 8771$.

Certain of the more interesting records are shown in Figures 3 to 15. Due to selective absorption by the earth's atmosphere, several broad areas of the 
infra-red solar spectrum are entirely masked, but three relatively transparent 'windows' are available for observation of solar and telluric lines. The location of the 'windows' is well shown in Langley's (1900) early map of the spectrum which is reproduced in Figure 2. The absorptions at $1.4 \mu$ and at $1.8 \mu$ are produced by water vapour, whereas the absorption at $2 \cdot 6 \mu$ is due both to water vapour and to carbon dioxide. The three transparent regions are centred approximately at $1.65 \mu$, at $2.20 \mu$ and at $3.3 \mu$. The absorption lines in the clear regions are divided between those that are formed in the earth's atmosphere and those that originate in the sun. The solar lines are easily distinguished from comparisons between tracings made with the sun at high and at low

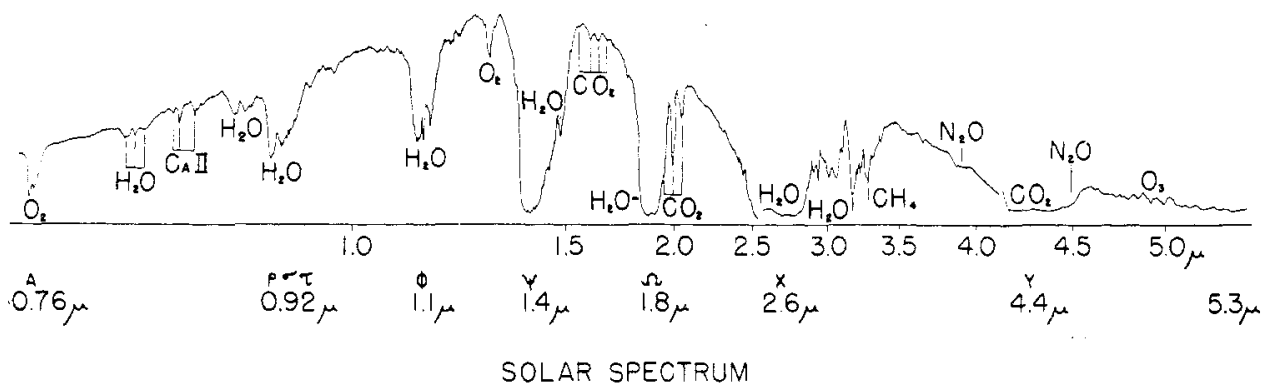

Figure 2. The solar spectrum as observed by S. P. Langley with the assistance of C. G. Abbot, 1898.

altitudes. Well over 400 solar lines have been newly discovered in this way, approximately $75 \%$ of them in the $1.65 \mu$ region of the spectrum. Although in the $1.65 \mu$ region the ratio of solar to telluric lines on noonday tracings is approximately $50 \%$, in the $2.20 \mu$ region the ratio is about $12 \%$, and at $3.3 \mu$ less than half a dozen solar lines have been found. The progressive reduction in numbers of observed solar lines with increasing wavelength may be ascribed in part to increased telluric absorption at the longer wavelengths, but more important reasons, relating to the structure of atoms and to the physics of the solar atmosphere, will be discussed later in this paper.

\section{\$4. SOLAR LINES}

Published laboratory data on the wavelengths of atomic lines in spectral regions beyond the infra-red photographic limit are exceedingly rare. The observations have been made with relatively insensitive bolometers and thermocouples, and usually with unsteady arcs as sources. Consequently, only the very strongest lines have been recorded and the measured wavelengths suffer from uncertainties as large as 2A. R. A. Fisher of Northwestern University (private communication) has recently developed a steady source for the FeI spectrum and is engaged in the mapping and analysis of the spectrum from $1.0 \mu$ to $3.0 \mu$, also employing a Cashman cell, Wilson amplifier, and Pfund-type spectrometer optics. Similar spectrometer and detector installations have been completed at the National Bureau of Standards by Humphreys and Plyler (1949) and at the Ohio State University by Nielsen and his co-workers (1949).

Pending the availability of accurate laboratory wavelengths, the McMathHulbert workers (Goldberg, Mohler and McMath 1949) have had recourse to the prediction of wavelengths from the tables of atomic energy levels compiled by Moore (1949). By this method, approximately 160 infra-red solar lines 
have been identified, or over one-third of the total found between 1.5 and $3.6 \mu$. The identified elements, all of which are known to be abundant in the solar atmosphere, are $\mathrm{H}, \mathrm{C}, \mathrm{Na}, \mathrm{Mg}, \mathrm{Al}, \mathrm{Si}, \mathrm{Ca}, \mathrm{Fe}, \mathrm{Mn}$ and $\mathrm{Ni}$. Only lines of neutral atoms have thus far been found in the infra-red spectrum.

The number of absorption lines identified for each element is given in Table 2.

Table 2. Elements present in the Infra-Red Solar Spectrum between $1 \cdot 5 \mu$ and $3 \cdot 6 \mu$

$\begin{array}{lcccccccccc}\text { Element } & \mathrm{H} & \mathrm{C} & \mathrm{Na} & \mathrm{Mg} & \mathrm{Al} & \mathrm{Si} & \mathrm{Ca} & \mathrm{Fe} & \mathrm{Mn} & \mathrm{Ni} \\ \text { No. of lines } & 3 & 9 & 4 & 7 & 5 & 48 & 11 & 64 & 2 & 8\end{array}$

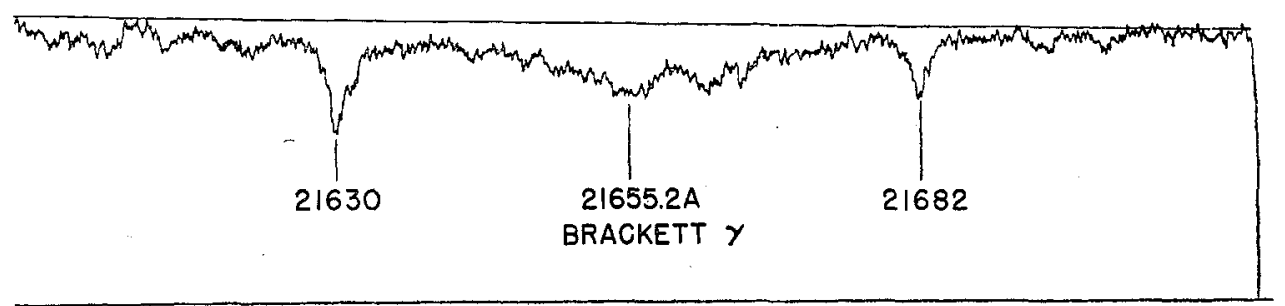

Figure 3. The third member of the Brackett series of hydrogen in the solar spectrum.
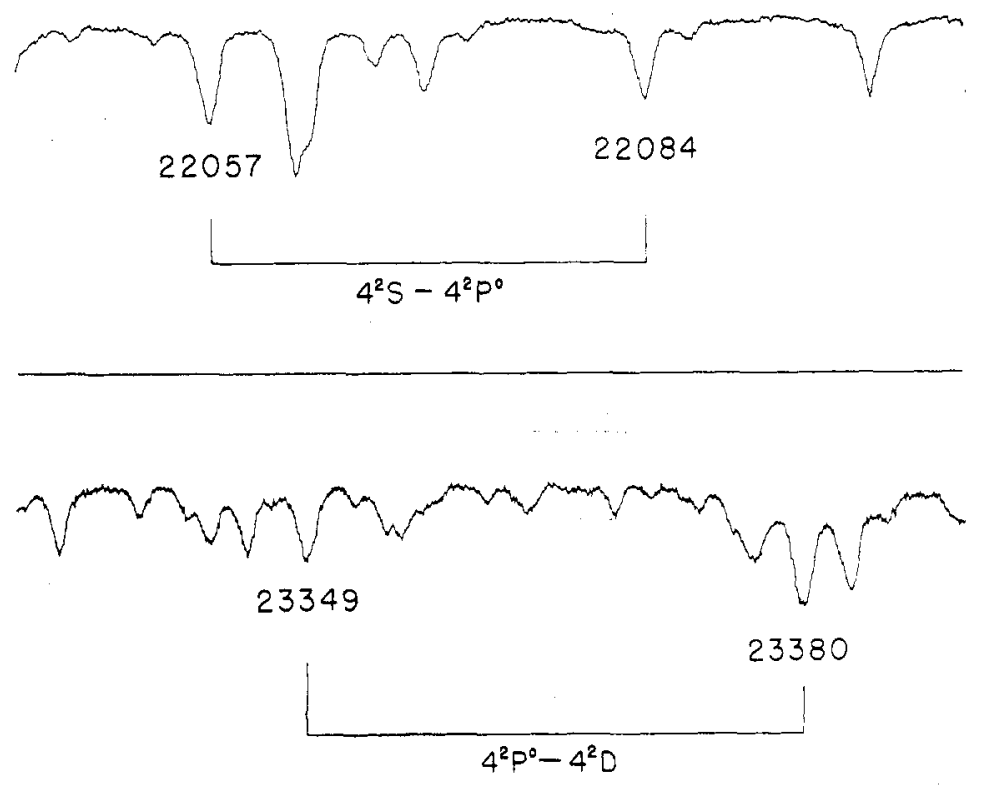

NAI

Figure 4. Na I lines in the infra-red solar spectrum. The horizontal line at the bottom of each. tracing in this and succeeding figures represents zero intensity.

The three lines of hydrogen are the third, seventh and eighth members of the Brackett series at $\lambda \lambda 16,407 \cdot 2,16,806 \cdot 6$ and $21,655.4$. The third member of the series is shown in Figure 3. The enormous width of the line, about $40 \mathrm{~A}$., is characteristic of hydrogen atoms subject to statistical Stark broadening, particularly when energy levels of high quantum numbers are involved. The 
widths of the Brackett series lines are also unusually great because of the fact that for given quantum numbers and field strengths the Stark widths are proportional to the square of the wavelength. The two higher members of the Brackett series are also extremely wide, and so shallow that they can barely be distinguished from the continuous spectrum.

The $\mathrm{NaI}$ doublet corresponding to the transition $4 \mathrm{~s}-4 \mathrm{p}$ at $\lambda \lambda 22,083$ and 22,056 is shown in Figure 4. The doublet $4 \mathrm{p}-4 \mathrm{~d}$ also appears prominently.
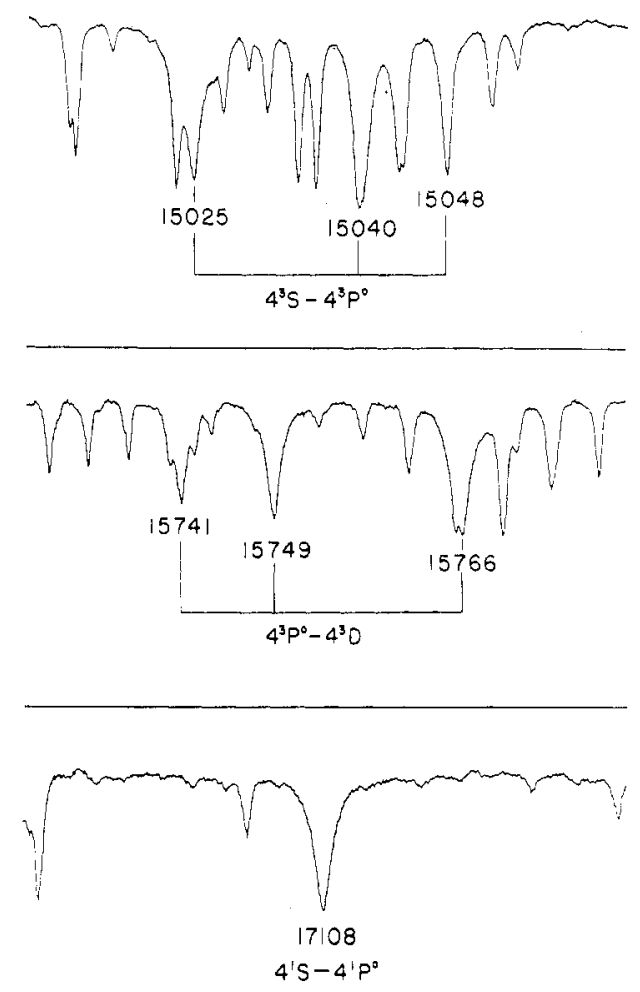

MG:

Figure 5. Neutral magnesium in the infra-red solar spectrum. Neighbouring lines are due to $\mathrm{H}_{2} \mathrm{O}$ at $\lambda 15,000$ and to $\mathrm{CO}_{2}$ at $\lambda 15,700$.

The lines of $\mathrm{MgI}$ are very wide and intense in the infra-red solar spectrum. The $4 s^{1} \mathrm{~S}-4 \mathrm{p}^{1} \mathrm{P}^{0}$ line at $\lambda 17,108 \cdot 5$ is the strongest solar infra-red line observed, with the exception of the third member of the Brackett series of hydrogen. Other interesting lines of $\mathrm{Mg} I$ are included in the multiplets $4 \mathrm{p}^{3} \mathrm{P}^{0}-4 \mathrm{~d}^{3} \mathrm{D}$ at $\lambda 15,750$ and $4 \mathrm{~s}^{3} \mathrm{~S}-4 \mathrm{p}^{3} \mathrm{P}^{0}$ at $\lambda 15,040$ (see Figure 5). Laboratory observations have disclosed only two members of each of the latter multiplets, the implication being that the ${ }^{3} \mathrm{P}^{0}$ levels $J=0$ and $J=1$ were not resolved. Evidence has been given (Goldberg, Mohler and McMath 1949), based primarily on agreement with the Landé interval rule, for the complete resolution of the $4^{3} \mathrm{P}^{0}$ term in the solar spectrum.

AlI is represented in the infra-red solar spectrum by the three lines of the multiplet $4 \mathrm{p}^{2} \mathrm{P}^{0}-4 \mathrm{~d}^{2} \mathrm{D}$ at approximately $\lambda 16,700$ and by the two members of 
the multiplet $4 p^{2} \mathrm{P}^{0}-5 s^{2} \mathrm{~S}$ at $\lambda 21,100$ (see Figure 6). The SiI lines (Figure 7) are among the strongest and most numerous in the entire infra-red spectrum. They occur in the regions of all three transparent windows including three lines at approximately $3 \cdot 3 \mu$.

The majority of the lines of CaI (Figure 8 ) appear near $2.0 \mu$ where they suffer from blending with the strong telluric lines of $\mathrm{CO}_{2}$. As in the photographic region of the spectrum, $\mathrm{Fe}_{\mathrm{I}}$ is the most abundant source of lines in the near infra-red, approximately 64 lines having been so identified. Only three or four multiplets of FeI (Figure 7) predicted from the term values of Russell,

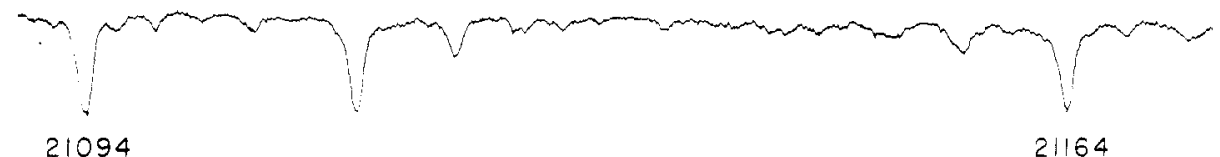

$4^{2} P^{0}-5^{2} S$

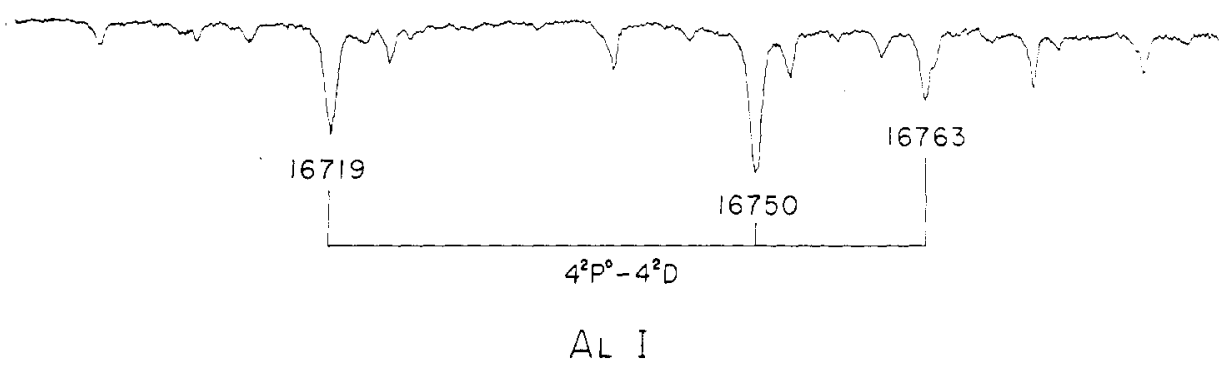

Figure 6. Solar infra-red lines of Als.

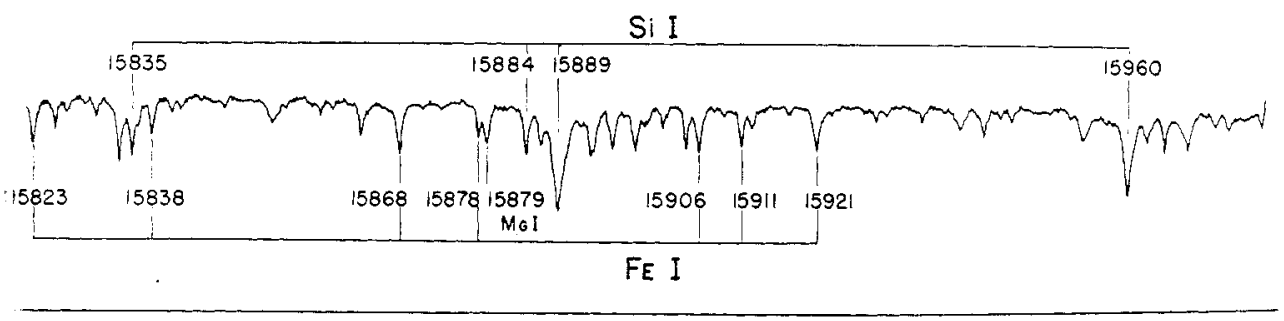

Figure 7. Solar infra-red lines chiefly of FeI and SiI.

Moore and Weeks (1944) are entirely normal in the sense that they obey all of the rules of LS coupling. The laboratory spectrum of FeI in the photographic region shows, however, that virtually any type of transition may be expected as long as it obeys the Laporte parity rule. In the absence of laboratory data and of theoretical intensities for the multiplet lines, however, the identifications of 'abnormal' multiplets are highly uncertain. It is estimated that as many as 100 solar lines, unidentified at present, will be identified with Fe I after the infra-red laboratory data become available. 
Additional lines of low ionization potential atoms, especially those of Ti I and VI, may be expected to appear in the infra-red sunspot spectrum. The Ti I multiplet $\mathrm{a}^{3} \mathrm{G}-\mathrm{z}^{3} \mathrm{G}^{0}$ appears to be present near $\lambda 15,500$ in the spectrum of a small sunspot recorded during the summer of 1948 (McMath and Goldberg 1949). A short section of the sunspot spectrum near $\lambda 15,900$ is shown in Figure 9, where it is compared with the disc spectrum at the same wavelengths.
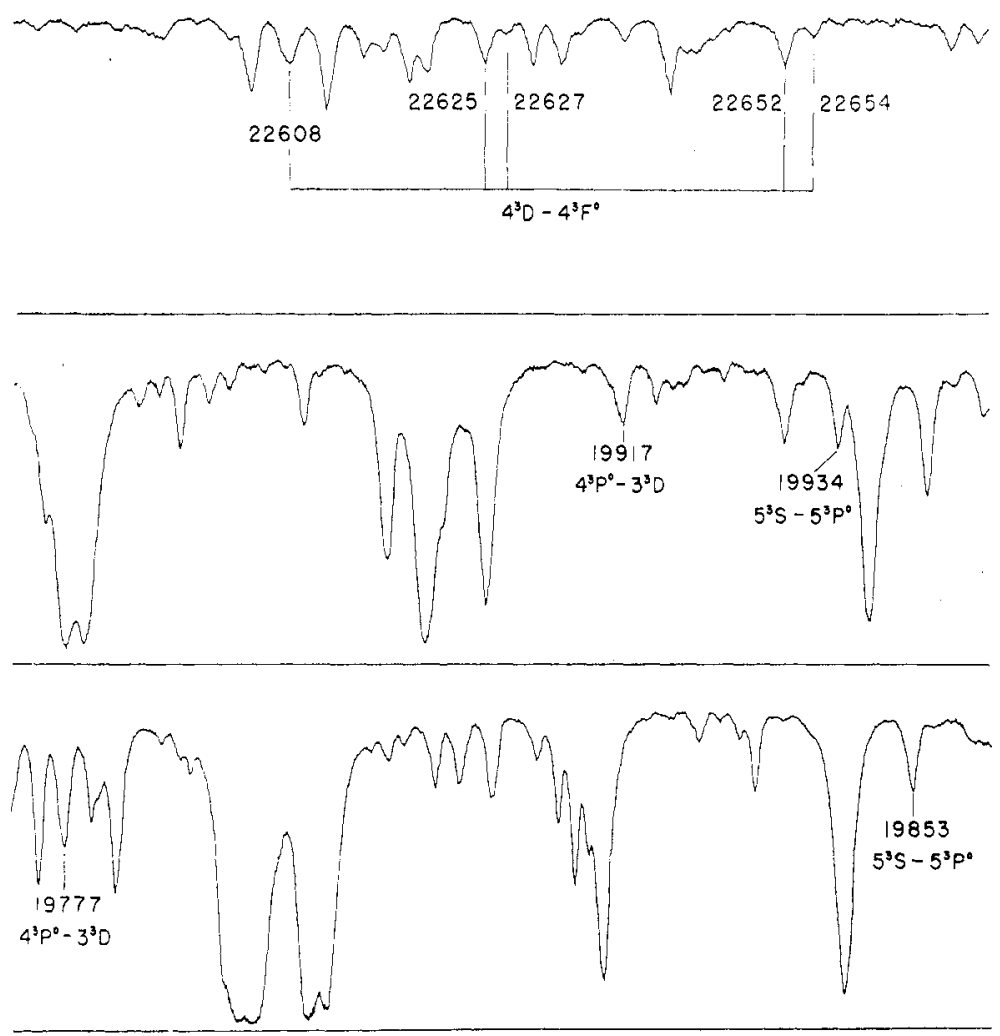

CA I

Figure 8. Solar infra-red lines of $\mathrm{Ca}$.

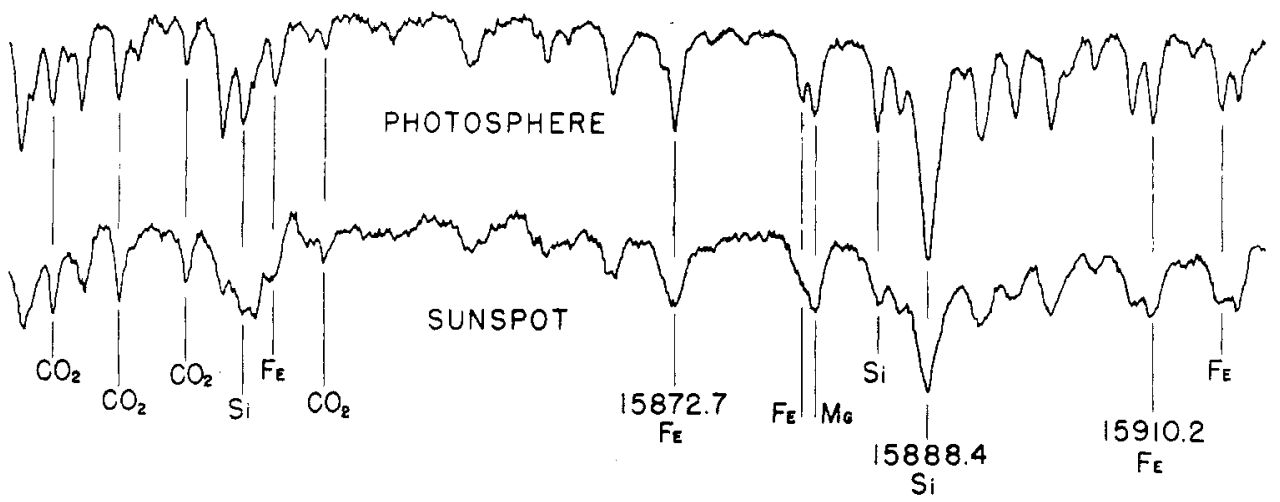

Figure 9. A section of the infra-red spectrum of a sunspot as compared with that of the reighbouring disc, 
It will be noted that whereas the telluric lines of $\mathrm{CO}_{2}$ are alike in appearance in both spectra, the solar lines of $\mathrm{Fe}, \mathrm{Si}$, and $\mathrm{Mg}$ are extremely wide in the spot spectrum. The widening is undoubtedly a result of the Zeeman effect of the sunspot's magnetic field. The infra-red spectrum offers interesting possibilities for the study of magnetic effects in the solar atmosphere in view of the fact that Zeeman splitting in wavelength units is proportional to the square of the wavelength.

\section{Factors Governing the Appearance of Solar Lines}

The most important factors governing the appearance of the spectral lines of a given element in the solar spectrum are $(a)$ its abundance, $(b)$ the excitation potential, and $(c)$ the continuous opacity of the solar atmosphere for the wavelength considered. As pointed out by Babcock and Moore (1947), most infra-red lines are of high excitation potential. Ultimate lines are rare or absent, and even penultimate lines occur infrequently. Approximately $90 \%$ of all lines identified in the infra-red solar spectrum between $1.5 \mu$ and $3.6 \mu$ have excitation potentials in excess of 5 volts. The lowest excitation potential observed is $2 \cdot 17$ volts for an inter-system line of FeI. Furthermore, there is a remarkable decrease in both the numbers and intensities of solar lines in the $2.2 \mu$ region as compared with those at $1.65 \mu$. Between 1.52, and $1.75 \mu$ about 300 solar lines with central absorptions higher than $4 \%$ have been found, or an average of about 0.32 lines per $\mathrm{cm}^{-1}$. On the other hand, the frequency of occurrence of lines with the same minimum intensity between $2 \cdot 1 \mu$ and $2 \cdot 4 \mu$ is about 0.11 per $\mathrm{cm}^{-1}$. This result lends strong support to the idea that the negative hydrogen ion is the major source of continuous opacity in the solar atmosphere.

Wildt (1939) first suggested the negative hydrogen ion as the source of opacity. Following earlier approximate calculations by several investigators, Chandrasekhar and Breen (1946) calculated with high accuracy the theoretical absorption coefficient for both bound-free and free-free transitions Simultaneously, Chalonge and Kourganoff (1946) ingeniously derived the observed variation with wavelength of the solar absorption coefficient from limb darkening observations by Abbot, Plaskett and Fabry. The observed and calculated curves, shown in Figure 10, are seen to agree closely between $\lambda 4000$ and $\lambda 16,000$, and to justify the conclusion (Chandrasekhar and Münch 1946) that $\mathrm{H}^{-}$is the principal source of solar opacity. The discrepancy at longer wavelengths is probably within the uncertainties of both the calculated absorption coefficient for free-free transitions and the limb-darkening observations. New limbdarkening measures are being secured at the McMath-Hulbert Observatory (Pierce 1949) with Cashman cells to a limit of $3.6 \mu$, and with the thermocouple to about $20 \mu$.

It will be noted from Figure 10 that, beginning at $\lambda 4000$, the absorption coefficient of $\mathrm{H}^{-}$rises to a maximum at about $\lambda 8600$ and thereafter decreases to a minimum at $\lambda 16,600$. At this point, the free-free transitions become important and the absorption curve increases steadily toward the longer wavelengths.

If we bear in mind that the production of high excitation infra-red lines is favoured by high temperature and also that the temperature increases with depth in the solar atmosphere, it is clear that the opacity minimum at $\lambda 16,600$ 
is highly favourable for the appearance of infra-red absorption lines. At longer wavelengths the increased opacity acts to screen the high temperature layers of the atmosphere, and on the average the infra-red lines will decrease both in numbers and in intensity.

The foregoing considerations are not in harmony with the tentative identification by Adel (1941 b) of five strong lines in the solar spectrum near $10 \mu$ as highlevel transitions in NaI and KI. Three lines, at $1,099.59 \mathrm{~cm}^{-1}, 1,101.33 \mathrm{~cm}^{-1}$, and $1,091.04 \mathrm{~cm}^{-1}$, are ascribed to the transition $3 \mathrm{~d}^{2} \mathrm{D}-4 \mathrm{p}^{2} \mathrm{P}^{0}$ in Na I. Although no line intensities are given, the appearance of the lines on the published reproductions of the tracings suggests that their total absorptions are of the order of $0.30 \mathrm{~cm}^{-1}$. On the other hand, the total absorptions of the lines of the $4 \mathrm{~s}-4 \mathrm{p}$

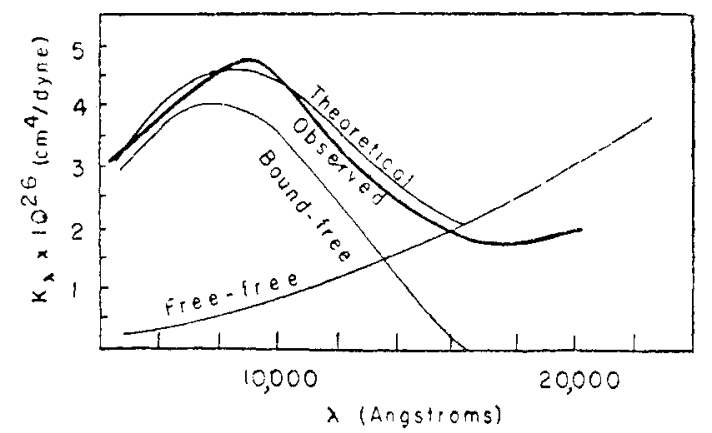

Figure 10. The absorption coefficient of the negative hydtogen ion per neutral $\mathrm{H}$ atom and per unit electron pressure at $T=6,300^{\circ} \mathrm{K}$., calculated by Chandrasekhar and Breen. The heavy curve is the observed coefficient by Chalonge and Kourganoff.

(Reproduced from a review article by $A . \mathcal{F}$. Deutsch, Rev. Mod. Phys., 1948, 20, 388).

doublet at $\lambda 22,000$ are approximately $0.050 \mathrm{~cm}^{-1}$. The f-value for the $3 \mathrm{~d}-4 \mathrm{p}$ transition has not been calculated, but in all probability is somewhat less than that for the $4 \mathrm{~s}-4 \mathrm{p}$ transition. Furthermore, the $3 \mathrm{~d}$ level lies about 0.4 volts above the $4 \mathrm{~s}$ level and the calculated continuous absorption coefficient at $9 \cdot 11 \mu$ is about 40 times greater than at $2 \cdot 21 \mu$. These circumstances are difficult to reconcile with the appearance of the $3 \mathrm{~d}-4 \mathrm{p}$ multiplet in the solar spectrum. The theoretical argument against the identification of three solar lines at about $1,175 \mathrm{~cm}^{-1}$ with the $6^{2} \mathrm{P}^{0}-5^{2} \mathrm{D}$ transition in $\mathrm{KI}$ is even more convincing. The solar lines are strong almost to the point of saturation. Yet the transition $4^{2} \mathrm{P}^{0}-3^{2} \mathrm{D}$, for which the lower excitation potential is less than that of $6^{2} \mathrm{P}^{0}-5^{2} \mathrm{D}$ by nearly two volts, appears in the solar spectrum at $\lambda 11,769$ with an extremely low Rowland intensity of -2 (Babcock and Moore 1947).

\section{\$5. TELLURIC LINES}

More than one-half of the lines in the region between $1.4 \mu$ and $3.6 \mu$ in the solar spectrum arise from absorption by molecules in the earth's atmosphere. At $1.4 \mu, 1.8 \mu$ and $2.6 \mu$, absorption by $\mathrm{H}_{2} \mathrm{O}$ and $\mathrm{CO}_{2}$ renders the atmosphere completely opaque. In the intervening regions the telluric absorption is much weaker but produces well defined band systems of $\mathrm{H}_{2} \mathrm{O}, \mathrm{CO}_{2}, \mathrm{CH}_{4}$ and $\mathrm{N}_{2} \mathrm{O}$. The near infra-red band systems of these molecules have recently been investigated by McMath, Goldberg, Mohler and Pierce, as described below. 


\section{(i) Carbon Dioxide}

The near infra-red absorption by molecules of carbon dioxide in the earth's atmosphere is plainly shown on early tracings of the solar spectrum. Langley (1900) recorded two bands at $2.01 \mu$ and $2.05 \mu$, which he designated as $\omega_{1}$ and $\omega_{2}$. Laboratory observations by Barker and Wu (1934) later revealed a third band at $1.95 \mu$ which is not apparent on Langley's tracing, due to strong absorption by water vapour. Adel (1943) later recorded all three bands with sufficient resolution to reveal their rotational structures. The band at $1.95 \mu$ was designated $\omega_{0}$ by Adel in conformity with Langley's notation. The $2 \mu$ bands result from transitions between the ground level of $\mathrm{CO}_{2}$ and the triad of excited vibrational levels $04_{0} 0,122_{0} 1$ and $20_{0} 1$, the excited levels being in Fermi resonance. Barker and $\mathrm{Wu}$ also recorded in the laboratory four weaker unresolved bands of $\mathrm{CO}_{2}$ at $1.54 \mu, 1.57 \mu, 1.60 \mu$ and $1.65 \mu$, which were later identified by Adel and Lampland (1938) with transitions between the ground level and the excited resonating levels $06_{0} 1,14_{0} 1,22_{0} 1$ and $30_{0} 1$. The $\mathrm{CO}_{2}$ bands at $1.6 \mu$ are plainly visible on Langley's early tracings and were recognized by Adel and Lampland as a single small absorption in the low-resolution prismatic solar spectrum.

All seven bands of $\mathrm{CO}_{2}$ appear fully resolved on the McMath-Hulbert tracings of the infra-red solar spectrum (see Figure 11). The high precision of the measured wave numbers has warranted an independent determination both of the equilibrium moment of inertia of $\mathrm{CO}_{2}$ and of the rotational constants $\alpha_{1}$, $\alpha_{2}$ and $\alpha_{3}$ (Goldberg, Mohler, McMath and Pierce 1949). The results are shown in Table 3, where they are compared with earlier determinations from

Table 3. Rotational Constants of $\mathrm{CO}_{2}$ in $\mathrm{cm}^{-1}$

\begin{tabular}{lccccc} 
& $\mathrm{B}_{\mathrm{e}}$ & $\mathrm{B}_{000}$ & $\mathrm{~B}_{\mathrm{e}} \alpha_{1}$ & $\mathrm{~B}_{\mathrm{e}} \alpha_{2}$ & $\mathrm{~B}_{\mathrm{e}} \alpha_{3}$ \\
Lake Angelus & 0.3920 & 0.3906 & -0.00103 & +0.000640 & -0.00306 \\
Dennison & 0.3925 & 0.3911 & 0.00058 & +0.00045 & -0.00307 \\
Herzberg & 0.3906 & $0.3895 *$ & -0.00056 & -0.00062 & -0.0029 \\
\multicolumn{5}{c}{ Newly revised value } & $0.39043 \mathrm{~cm}^{-1}$.
\end{tabular}

other infra-red bands by Dennison (1940) and Herzberg (1945). In the main, the agreement with Dennison's results is excellent. Herzberg (1948) has recently secured new results from a study of the photographic infra-red bands of $\mathrm{CO}_{2}$ that agree quite closely with the McMath-Hulbert results. For example, his new value of $\mathrm{B}_{000}$ is 0.39043 as compared with the McMath-Hulbert value of 0.3906 .

The great strength of the $2 \mu$ bands of $\mathrm{CO}_{2}$ suggests the presence in the spectrum of isotope bands resulting from similar transitions in the molecules ${ }^{13} \mathrm{C}^{16} \mathrm{O}_{2}$ and ${ }^{12} \mathrm{C}^{16} \mathrm{O}^{18} \mathrm{O}$, the relative abundances of the isotopes ${ }^{13} \mathrm{C}$ and ${ }^{18} \mathrm{O}$ being $1.1 \%$ and $0.2 \%$ respectively. The presence of such bands on the laboratory tracings of Barker and Wu is suggested by a small dip in the continuous spectrum in the space between the $\mathrm{CO}_{2}$ bands at $2.01 \mu$ and $2.05 \mu$. The infra-red solar spectrum obtained at Lake Angelus has a series of faint but clearly resolved bands adjacent to and superposed on the bands of ordinary $\mathrm{CO}_{2}$ (see Figure 12). A total of six isotope bands would be expected to appear at $2 \mu$, three each corresponding to the two isotopic forms of $\mathrm{CO}_{2}$. As compared with the bands of ordinary $\mathrm{CO}_{2}$ the isotope bands should be shifted to lower frequencies by varying amounts from $57 \mathrm{~cm}^{-1}$ to $115 \mathrm{~cm}^{-1}$. Five of the six expected bands have been found (Goldberg, Mohler and McMath 1948) in very nearly the 

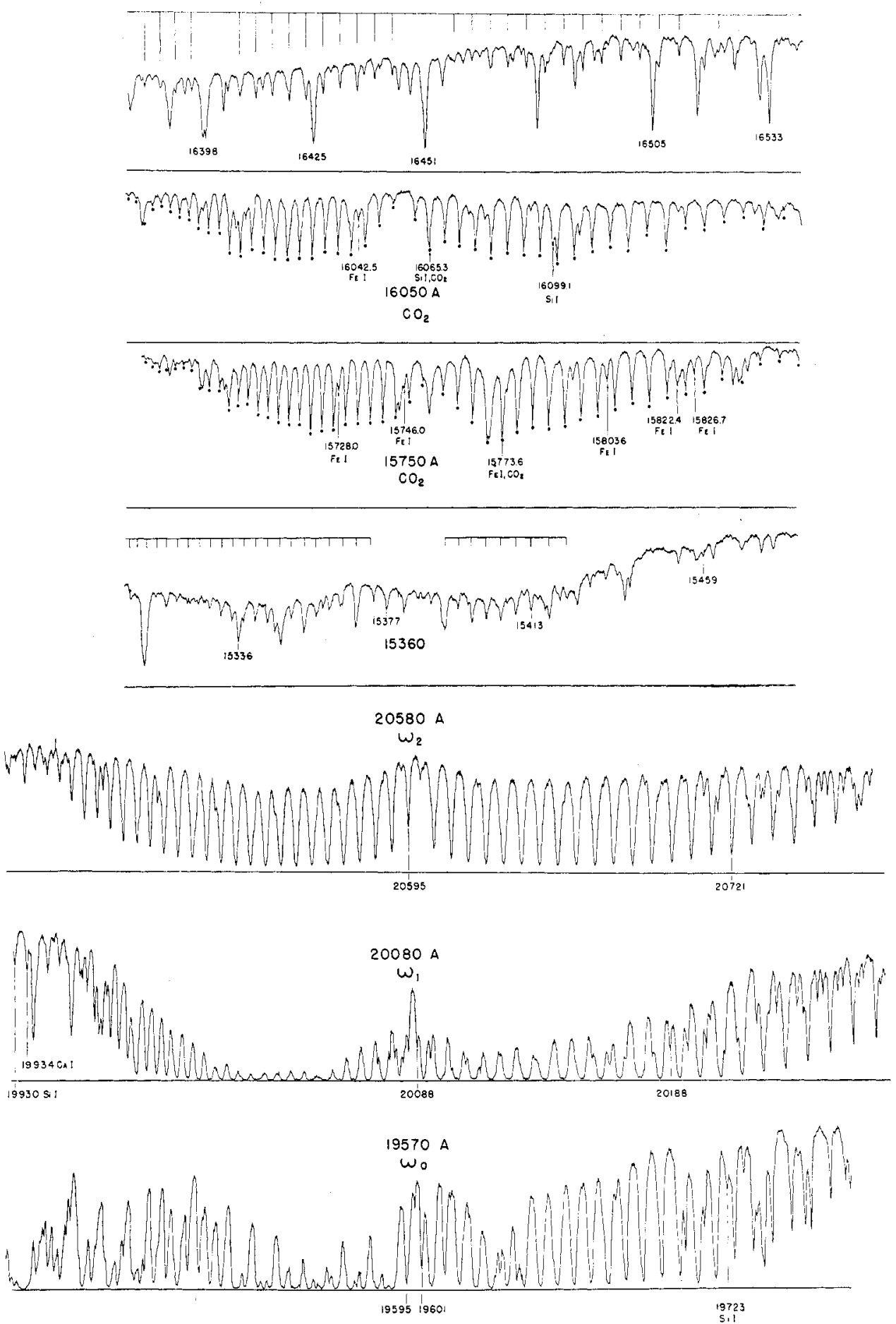

Figure 11. Telluric combination bands of $\mathrm{CO}_{2}$ at $1.6 \mu$ and at $2 \mu$. The lines of Fe I, $\mathrm{Si} \mathrm{I}$ and $\mathrm{Ca}$ are of solar origin. The regularly-spaced series of lines at $\lambda \lambda 16,398,16,425,16,451$ etc., are members of the R-branch of the $2 v_{3}$ band of $\mathrm{CH}_{4}$ (see Figure 14). 

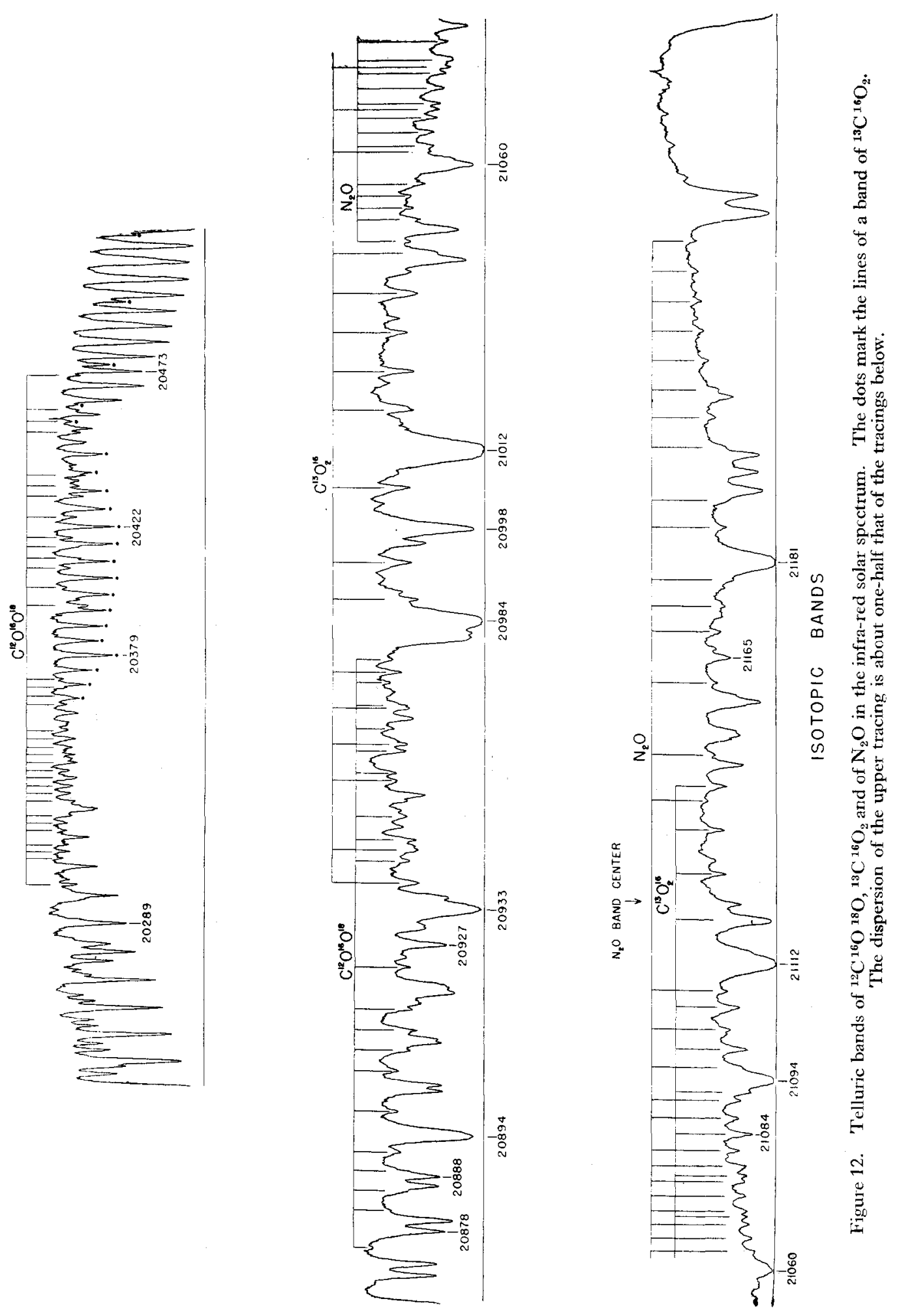


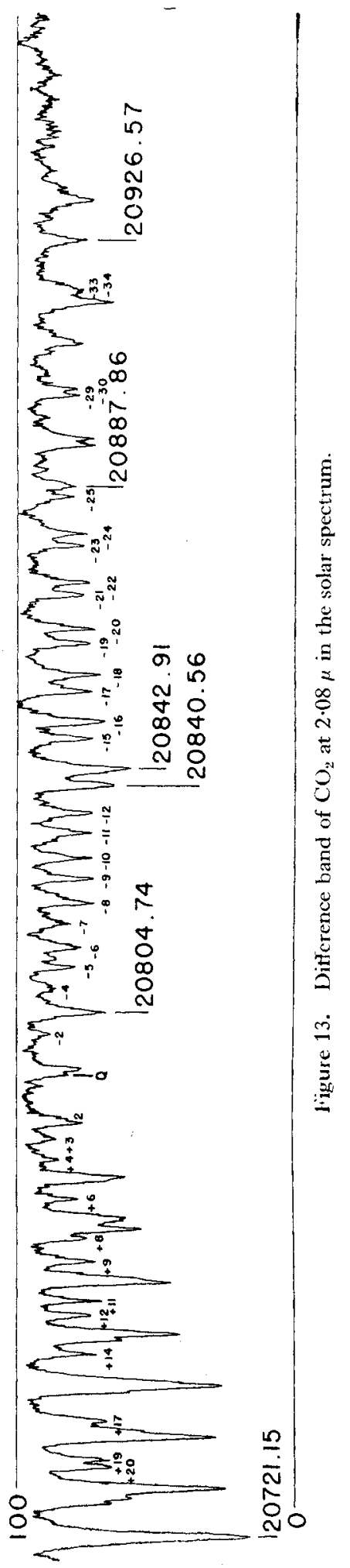


calculated positions, the sixth band being submerged by the strong band $\omega_{1}$. Furthermore, the bands of ${ }^{13} \mathrm{C}^{16} \mathrm{O}_{2}$ have identical rotational spacings, as compared with the main bands of ${ }^{12} \mathrm{C}^{16} \mathrm{O}_{2}$, whereas the bands of ${ }^{12} \mathrm{C}^{16} \mathrm{O}^{18} \mathrm{O}$ have approximately one-half the usual spacing. These results are in accord with theory, since substitution of an atom of ${ }^{18} \mathrm{O}$ for one of ${ }^{16} \mathrm{O}$ destroys the symmetry of the $\mathrm{CO}_{2}$ molecule and results in the appearance of alternate rotational lines which are absent for the symmetrical molecule.

Two additional new bands of $\mathrm{CO}_{2}$ have been found in the solar spectrum (McMath and Mohler 1948) at 2.01 $\mu$ and 2.08 $\mu$ and have been identified (Mohler, McMath and Goldberg 1949) as belonging to the triad of resonating bands that originate from the excited vibrational level $01_{1} 0$ and terminate in the levels $05_{1} 1,13_{1} 1$ and $21_{1} 1$ (see Figure 13). The third member of the group at $5,131.6 \mathrm{~cm}^{-1}$ is blended with the strong band $\omega_{0}$, although numerous individual lines appear to be present. The difference bands are interesting in that they display the $l$-type doubling characteristic of $\pi-\pi$ transitions. Analysis of the rotational structures leads to a value for the l-type doubling constant $q=0.00051 \mathrm{~cm}^{-1}$, which is to be compared with Herzberg's (1945) determination, from other infra-red bands, of $q=0.00034 \mathrm{~cm}^{-1}$.

Data relating to the 13 bands of $\mathrm{CO}_{2}$ observed in the near infra-red solar spectrum are given in Table 4 . The first column gives the designation of each

Table 4. $\mathrm{CO}_{2}$ Bands in the Infra-Red Solar Spectrum

(The dashes refer to bands predicted but not observed due to obscuration by other bands of $\mathrm{CO}_{2}$ and by $\mathrm{H}_{2} \mathrm{O}$.)

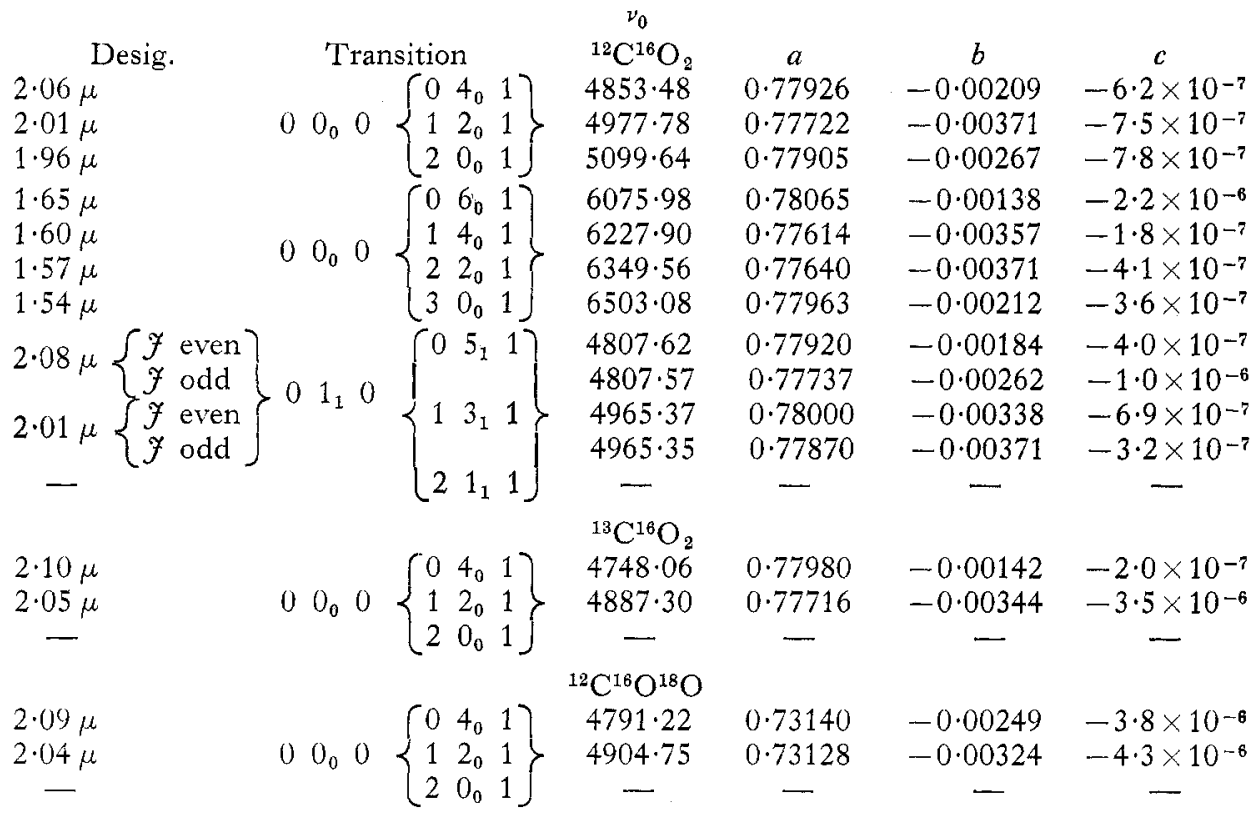

band, and the second column the quantum numbers involved in the transitions. The third, fourth, fifth and sixth columns give the constants of the least squares solutions of the equation representing the rotational structures, viz.:

$$
\nu=\nu_{0}+a m+b m^{2}+c m^{3},
$$


where $m=-J$ for the negative branch and $m=J+1$ for the positive branch. For all transitions from the ground state of ${ }^{12} \mathrm{C}^{16} \mathrm{O}_{2}$ and of ${ }^{13} \mathrm{C}^{16} \mathrm{O}_{2}$, only even values of $J$ are permitted. For the difference bands of ${ }^{12} \mathrm{C}^{16} \mathrm{O}_{2}$ and those of ${ }^{12} \mathrm{C}^{16} \mathrm{O}^{18} \mathrm{O}$ both even and odd values of $J$ are allowed.

(ii) Methane

Spectroscopic evidence for the presence of methane in the earth's atmosphere was first reported by Migeotte (1948) from observations of the P-branch of the

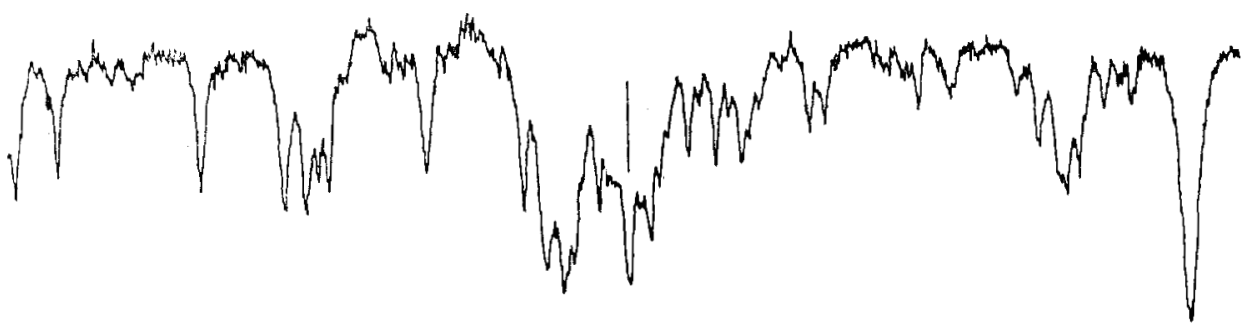

$4217 \nu_{1}+\nu_{4}$

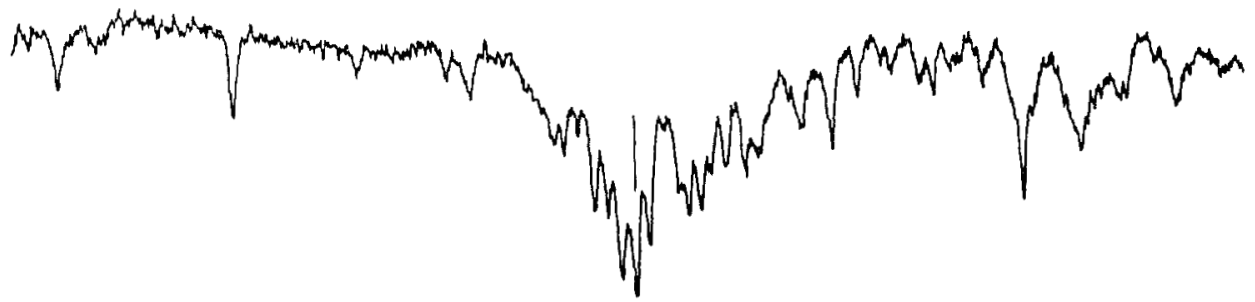

$4313 \nu_{3}+\nu_{4}$

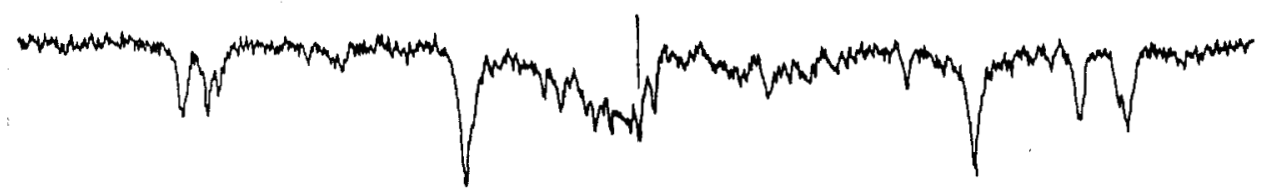

$4546 \nu_{2}+\nu_{3}$

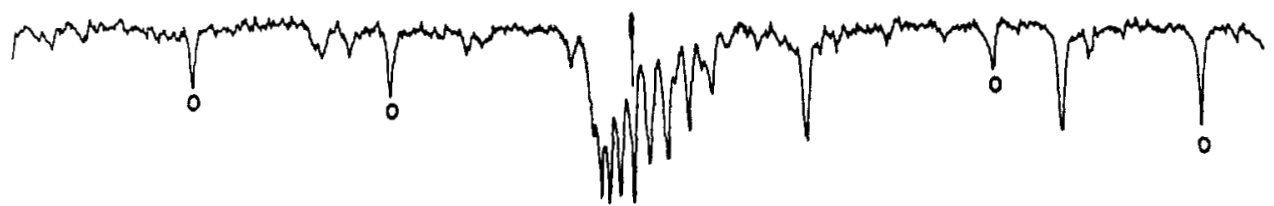

$60022 \nu_{3}$

Figure 14. Q-branches of overtone and combination branches of telluric $\mathrm{CH}_{4}$ bands in the solar spectrum. The band centres are in $\mathrm{cm}^{-1}$.

$\nu_{3}$ fundamental at $3.3 \mu$ with grating and thermocouple. Independent confirmation was afforded by the detection of the first overtone, $2 \nu_{3}$, at $1.66 \mu$ by McMath, Mohler and Goldberg (1948) with the PbS cell. The latter also succeeded in observing the Q-branches of the combination bands $\nu_{1}+\nu_{4}, \nu_{3}+\nu_{4}$, and $\nu_{2}+\nu_{3}$ at $2 \cdot 20 \mu, 2.32 \mu$ and $2.37 \mu$, respectively (see Figure 14). Later, Mohler and 
Pierce (1949) employed a refrigerated Cashman $\mathrm{PbS}$ cell to map the region $2 \cdot 9-3 \cdot 6 \mu$ with considerably improved resolution, sufficient to separate several lines of the R-branch of the $\nu_{3}$ band and to reveal the multiplicity characteristic of the high series members (see Figure 15). Adel (1949) has also reported the presence of the P-branch of $\nu_{3}$ on records obtained at the Lowell Observatory in 1941.

Recently McMath, Mohler, Pierce and Goldberg (1949) have detected additional faint bands of $\mathrm{CH}_{4}$ in the solar spectrum at $1.71 \mu, 1.73 \mu$ and $2.43 \mu$. The four bands in the $2 \mu$ region account for approximately 330 telluric lines in the solar spectrum between $2 \cdot 15 \mu$ and $2 \cdot 45 \mu$ on tracings obtained at various air masses from 1 to about 8 . It is estimated that between one-third and one-half this number of lines would be present on noonday tracings. The weak bands at $1.71 \mu$ and $1.73 \mu$ require a path length of about 3 air masses for their appearance in the solar spectrum. The $2 \nu_{3}$ band of $\mathrm{CH}_{4}$ in the solar spectrum, as recorded at the McMath-Hulbert Observatory, is shown in Figure 14. The Q-branch is seen to be fully resolved. McMath, Mohler and Goldberg (1949) have analysed the rotational structure of the $2 \nu_{3}$ band and have obtained a value of 5.163 for the average half spacing $B_{0}$. The same value has been derived by Nelson, Plyler and Benedict (1948) from analyses of laboratory tracings secured at Northwestern University with a Cashman cell and Wilson amplifier. The abundance of $\mathrm{CH}_{4}$ in the earth's atmosphere has been determined (McMath and Goldberg 1949) from comparisons between the intensities of the absorption lines of the $2 \nu_{3}$ band in the solar spectrum with those secured in the laboratory with an artificial source and a known quantity of gas. The absorption with zenith sun is found to be equivalent to that which would be produced by a layer of methane $1.1 \mathrm{~cm}$. thick at normal temperature and pressure. From the relative intensities of the members of the $\mathrm{P}$ and $\mathrm{R}$ branches, a Boltzmann temperature of $-33^{\circ} \mathrm{c}$. has been deduced. The physical meaning of the temperature found must remain doubtful until knowledge is obtained concerning the vertical distribution of methane in the earth's atmosphere. Information concerning the vertical distribution will be forthcoming as a result of abundance determinations which are now in progress at Mount Wilson, where the elevation is approximately 6,000 feet.

\section{(iii) Nitrous Oxide}

Spectroscopic evidence for the presence of nitrous oxide in the earth's atmosphere was first given by Adel (1939) through recognition of the $\nu_{1}$ fundamental at $7.8 \mu$. The presence of atmospheric $\mathrm{N}_{2} \mathrm{O}$ has recently been confirmed by observation of additional bands at $3.9 \mu, 4.5 \mu$ and $8.6 \mu$ by Migeotte (1949) and at $3.9 \mu, 4.1 \mu$ and $4.5 \mu$ by Shaw, Sutherland and Wormell (1948). Observations with Cashman cells at both the McMath-Hulbert and Mount Wilson Observatories have also revealed four additional bands of $\mathrm{N}_{2} \mathrm{O}$ in the solar spectrum between $2 \cdot 0$ and 3.0 (McMath and Goldberg 1949). Three of the bands have previously been observed in the laboratory by Plyler and Barker $(1931,1932)$, namely, $2 \nu_{1}+\nu_{3}$ at $2 \cdot 13 \mu, 2 \nu_{3}$ at $2 \cdot 26 \mu$, and $2 \nu_{2}+\nu_{3}$ at $3 \cdot 0 \mu$. The appearance of the $2 \cdot 13 \mu$ band in the solar spectrum is shown in Figure 12 . The fourth band, which is extremely weak, lies at $2 \cdot 16 \mu$ and was found on a Mount Wilson tracing obtained with the sun just above the horizon. The identification of the band was established from a high resolution laboratory 

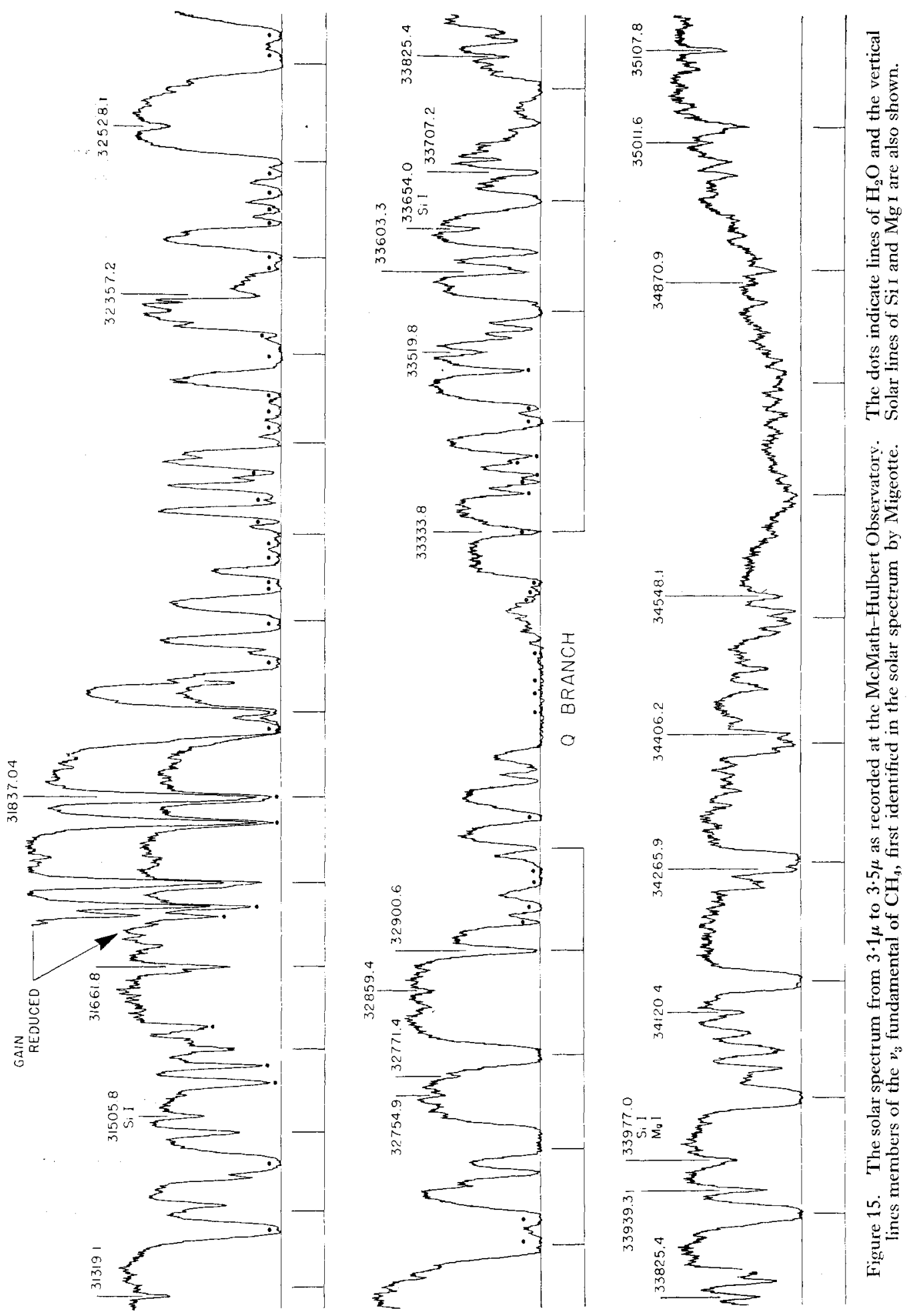
tracing made with an absorption cell containing $25 \mathrm{~cm}$. of $\mathrm{N}_{2} \mathrm{O}$ at atmospheric pressure. The laboratory record also discloses a second faint band overlapping the negative branch of the $2 \nu_{3}$ overtone at $2 \cdot 26 \mu$.

The abundance of $\mathrm{N}_{2} \mathrm{O}$ in the earth's atmosphere has been determined (McMath and Goldberg 1949) from a comparison between the intensities of the lines of the $2.13 \mu$ band in the solar spectrum and as produced by a known amount of $\mathrm{N}_{2} \mathrm{O}$ in the laboratory. The telluric absorption is equivalent to that which would be produced by $4 \mathrm{~mm}$. of the gas at normal temperature and pressure.

\section{(iv) Water Vapour}

Because of the long path of sunlight through the earth's atmosphere, the solar spectrum contains numerous overtone and combination bands of $\mathrm{H}_{2} \mathrm{O}$ that are not ordinarily observed in the laboratory. The rotational analysis of the telluric lines of water vapour appearing on the McMath-Hulbert tracings has been undertaken by W. S. Benedict. Preliminary results have been published (Mohler and Benedict 1948) for three newly resolved bands, $2 \nu_{2}+\nu_{3}$ at $6,871 \cdot 37 \mathrm{~cm}^{-1}, \nu_{1}+2 \nu_{2}$ at $6,775 \cdot 00 \mathrm{~cm}^{-1}$, and $3 \nu_{2}$ at $4,666 \cdot 70 \mathrm{~cm}^{-1}$.

\section{ACKNOWLEDGMENTS}

I am indebted to Dr. G. B. B. M. Sutherland for reading the manuscript, and to Dr. O. C. Mohler for many of the early historical references.

\section{REFERENCES}

Abbot, C. G., and Freeman, H. B., I929, Smith. Misc. Coll., 82, No. I.

Abney, W. DE W., I880, Phil. Trans. Roy. Soc., 171, 653; 1886, Ibid., 177, 457.

ADEL, A., I939, Astrophys. F., 90, 627; I 94 I a, Ibid., 94, 45I ; I94I b, Ibid., 94, 449; I942, Ibid., 96, 239; 1943, Ibid., 97, I90; I949, Phys. Rev., 75, 322.

Adel, A., and Lampland, C. O., 1938, Astrophys. 7 ., 87, 198.

BabCock, H. D., and Moore, C. E., 1947, Carnegie Inst. Wash. Publ., 579.

Barker, E. F., and Wu, T. Y., I934, Phys. Rev., 45, I.

Becquerel, A. E., r843, Ann. Chim. Phys., Ser. 3, 9, 314; 1848, Ibid., 22, 344; I869, C.R. Acad. Sci., Paris, 69, 995; 1873, Ibid., 77, 302; 1876, Ibid., 83, 249; I877, Ann. Chim. Phys., Ser. 5, 22, 360.

Becquerel, A. H., I883, Ann. Chim. Phys., Ser. 5, 30, 5 .

BRACKeTt, F. S., I92I, Astrophys. F., 53, I2I.

BurNs, K., I920, Lick Obs. Bull., 10, 64.

Cashman, R. J., 1946, F. Opt. Soc. Amer., 36, 356 A.

Chalonge, D., and Kourganoff, V., I946, Ann. d'Astrophys., 9, 69.

Chandrasekhar, S., and Breen, F. H., I946, Astrophys. $\mathcal{F}$., 104, 430.

Chandrasekhar, S., and Münch, G., 1946, Astrophys. $\mathscr{7} ., 104,446$.

Dennison, D. M., I940, Rev. Mod. Phys., 12, I75.

Draper, J. W., I843, Phil. Mag., Ser. 3, 22, 360; 188r, Ibid., Ser. 5, 11, 157.

Foucault, L., and Fizead, H. L., I847, C.R. Acad. Sci., Paris, 25, 447.

Fowle, F. E., 1917, Smith Misc. Coll., 68, No. 8.

Goldberg, L., Mohler, O. C., and McMath, R. R., I948, Phys. Rev., 74, i88 i; i949, Astrophys. F., 109, 28.

Goldberg, L., Mohler, O. C., McMath, R. R., and Pierce, A. K., i949, Phys. Rev., 76, I 848 .

Herschel, J, i 840 , Phil. Trans., 130, i.

Herschel, W., 1800, Phil. Trans., 90, 284, 437.

Herzberg, G., 1945, Infra-Red and Raman Spectra (New York : D. Van Nostrand), p. 395; I 948, Astronom. F., 54, 75 .

Higgs, G., 1898, Astrophys. $\mathscr{F} ., 7,86$. 
Humphreys, C. J., and Plyler, E. K., 1949. (Reported at June Symposium on Molecular Structure, held at Ohio State University.)

Kuiper, G., Wilson, W., and Cashman, R. J., 1947, Astrophys. F., 106, 246.

Lamansky, S., i 872 , Phil. Mag., Ser. 4, 43, 282.

Langley, S. P., I881, Proc. Amer. Acad. Sci., 16, 342; I900, Ann. Smith. Inst., I.

McMath, R. R., and Goldberg, L., 1949, Proc. Amer. Phil. Soc., 93, 362.

McMath, R. R., and Mohler, O. C., I948, Pub. Astr. Soc. Pac., 60, i i9; 1949, F. Opt. Soc. Amer., 39, 903.

McMath, R. R., Mohler, O. C., and Goldberg, L., I948, Phys. Rev., 73, 1203; I949, Astrophys. F., 109, 17 .

McMath, R. R., Mohler, O. C., Pierce, A. K., and Goldberg, L., I 949, Phys, Rev., 76, I 533 .

Meggers, W. F,, I9I8, Astrophys. F., 47, I.

Migeotte, M., I945, Thèse, Liége; I948, Phys. Rer., 73, 5 I9, Astrophys. F., 107, 400; I949, The Atmospheres of the Earth and Planets (Chicago: University of Chicago Press), p. 284.

Minnaert, M., Mulders, G. F. W., and Houtgast, J., i940, A Photometric Atlas of the Solar Spectrum (Amsterdam : Schnabel, Kampert and Helm).

Mohler, O. C., and Benedict, W. S., i 948, Phys. Rev., 74, 702.

Mohler, O. C., McMath, R. R., and Goldberg, L., I949, Phys. Rev., 75, 520.

Mohler, O. C., and Pierce, A. K., i 949, Pub. Astr. Soc. Pac., 61, 22 I.

Moore, C. E., i 949, Atomic Energy Levels, Nat. Bur. Stand. Circ. 467.

Nelson, R. C., Plyler, E. K., and Benedict, W. S., i 948, F. Res. Nat. Bur. Stand., Wash., $41,6{ }_{5}$.

Nielsen, H. H., 1949. (Reported at June Symposium on Molecular Structure, held at Ohio State University.)

Nobili, L., r83 i, Pogg. Ann., 24, 640.

Pierce, A. K., I949, Pub. Astr. Soc. Pac., 61, 217.

Plyler, E. K., and Barker, E. F., I93 I, Phys. Rev., 38, I827; I932, Ibid., 41, 369.

Russell, H. N., Moore, C. E., and Weeks, D. W., 1944, Trans. Amer. Phil. Soc., 34, Part II.

St, John, C. E., Moore, C. E., Ware, L. W., Adams, E. F., and Babcock, H. D., I928, Carnegie Inst. Wash. Publ., 396.

Seebeck, T. J., I826, Pogg. Ann., 6, r $33,263$.

Shaw, J. H., Sutherland, G. B. B. M., and Wormell, T. W., i 948, Phys. Rev., 74, 978.

Starkiewicz, J., Sosnowski, L., and Simpson, O., I946, Nature, Lond., 158, 28.

Sutherland, G. B. B. M., Blackwezl, D. E., and Fellgett, P. B., i 946, Nature, Lond., 158,873 .

Svanberg, A. F., 1857, Pogg. Ann., 84, $4 \mathrm{I} 1$.

Wildt, R., r939, Astrophys. $7 ., 89,295$. 